(c) American Dairy Science Association, 2006.

\title{
Effects of Nonadditive Genetic Interactions, Inbreeding, and Recessive Defects on Embryo and Fetal Loss by Seventy Days
}

\author{
P. M. VanRaden and R. H. Miller \\ Animal Improvement Programs Laboratory, Agricultural Research Service, USDA, Beltsville, MD 20705-2350
}

\begin{abstract}
Lethal recessive genes that cause early embryo loss are difficult to detect. Nonreturn rate at $70 \mathrm{~d}$ after first insemination (NR) was evaluated as a trait of the embryo using $1,739,055$ first-service records from 1,251 Holstein bulls represented as both service sires and sires of cows. Effects modeled included herd-yearseason, parity of cow, sire of cow, service bull, interaction of service bull with sire of cow, and regression on inbreeding of embryo. Variances of service bull and sire of cow were estimated using REML and estimated effects were removed from the data. Interaction variance was estimated from the residuals using the tildehat approximation to REML. An additive relationship matrix was used for sire of cow and a dominance relationship matrix for the interaction term. Service bull effects were assumed constant across time and unrelated. For each $10 \%$ increase in inbreeding, NR percentage declined by an estimated $1 \%$. A regression of this size could be explained by $>20 \%$ of animals carrying defects that cause early embryo loss. Of the total variance, service bull contributed $0.36 \%$; sire of cow, $0.24 \%$ (heritability of $1.0 \%$ ); and interaction, $0.18 \%$ (dominance variance of $2.8 \%$ ). Numbers of records exceeded 500 for 50 bull pair subclasses. Predicted interactions that included effects of inbreeding ranged from $-3.6 \%$ to $+2.9 \%$, compared with the mean NR of $56 \%$. The largest negative interactions were not caused by known recessive defects. Complex vertebral malformation generally causes loss of pregnancies later in gestation, and few current bulls carry the gene for deficiency of uridine monophosphate synthase. Further study of the families with largest negative interactions could uncover new recessive defects.
\end{abstract}

Key words: nonreturn rate, recessive defect, inbreeding, dominance

\section{INTRODUCTION}

Many studies have investigated embryo losses, but few have examined the genetic factors that may cause

Received December 30, 2005.

Accepted February 3, 2006.

${ }^{1}$ Corresponding author: paul@aipl.arsusda.gov them. Embryo losses from conception to $42 \mathrm{~d}$ are 30 to $40 \%$ in most domestic species (Zavy and Geisart, 1994), but Wijeratne (1973) found $20.3 \%$ mortality among 280,215 embryos of dairy and beef breeds. Losses in cattle vary by stage of pregnancy, with most deaths occurring after $7 \mathrm{~d}$ of gestation (Ayalon, 1981) but before 15 to $17 \mathrm{~d}$ (Santos et al., 2004) and decreasing progressively after $28 \mathrm{~d}$ of pregnancy (Vasconcelos et al., 1997). Failed inseminations, missed heats, and unusual estrous cycles make these losses difficult to detect. Genetic causes of embryo loss include chromosomal defects, individual genes, and genetic interactions.

Chromosomal defects cause significant losses, especially in the first $90 \mathrm{~d}$ (Nino-Soto and King, 2004). One of the first structural chromosomal abnormalities identified in cattle was a 1/29 Robertsonian translocation (Gustavsson, 1979) present in several beef breeds and Scandinavian Red breeds but not in Holsteins. Because heterozygous females had reduced fertility, bulls carrying the 1/29 translocation were screened and eliminated during the 1970s. In a study using slaughterhouse ovaries of subfertile cows, Iwasaki and Nakahara (1990) found chromosomal abnormalities in $37.5 \%$ of bovine embryos cultured in vitro and in $28 \%$ of embryos cultured in vivo. Natural selection may favor spontaneous abortion of defective embryos so that females devote more resources to producing healthy offspring.

Genetic defects visible at birth are easier to study than are those causing losses earlier in gestation. The Multistate Project S-284 summary (2002) stated "Unknown defect genes may be hiding within reproductive or metabolic paths not directly observable or may arise from new mutations. If such genes exist, research to find them could be a wise investment." Two major recessive defects affecting embryo/fetal survival have been detected in Holsteins. Deficiency of uridine monophosphate synthase (DUMPS) was discovered over 20 yr ago (Robinson et al., 1984). A homozygous recessive condition, this deficiency causes embryonic death at 40 to $50 \mathrm{~d}$ of gestation (Shanks and Robinson, 1989). Testing for DUMPS among sires in AI has greatly reduced the frequency of heterozygous sires and of homozygous recessive embryos. 
Complex vertebral malformation (CVM) is another lethal recessive condition that causes pregnancy loss during gestation, with few homozygous embryos surviving to term (Agerholm et al., 2001). The CVM defect gene was widely disseminated through use of the bull Carlin-M Ivanhoe Bell and may have increased due to an association with yield traits (Kuhn et al., 2005). Persson (2003) studied 228 AI bulls in Sweden, and $23 \%$ were carriers of CVM. Carriers had significantly lower breeding values for nonreturn rate (NR) than noncarriers at $168 \mathrm{~d}$, but differences were not significant at 28 and $56 \mathrm{~d}$. Sattler (2002) described US efforts to test and control for CVM. As of August 2001, 18\% of US Holstein bulls marketed were CVM carriers. Today, nearly all bulls with suspect pedigrees are tested for CVM, and only 8 of 2,970 progeny test bulls born after $2002(<1 \%)$ are known carriers.

Additive genetic variance in reproductive traits is small, and heritabilities of all reproductive traits of dairy cattle are $10 \%$ or less (Warwick and Legates, 1979). Weigel and Rekaya (2000) reported heritabilities for reproductive traits ranging from 1.0 to $4.1 \%$ for Holstein cows, with service sire effects contributing 0.3 to $0.5 \%$ of phenotypic variance for 60 - or 90 -d NR. Cassell et al. (2003) and Clay et al. (2003) found heritabilities of 1 to $2 \%$ for $70-d$ NR in Holsteins and Jerseys. VanRaden et al. (2004) reported heritabilities of 1, 1.8, $6.6,4$, and $10 \%$ for $70-\mathrm{d}$ NR, number of services, days to first breeding, days to last breeding, and gestation length, respectively. Similar estimates have been obtained in many other countries.

Nonadditive genetic variance in reproductive traits of purebred populations has been estimated in few studies. Recessive genetic defects affecting pregnancy loss should contribute to dominance variance in nonreturn rate. Hoeschele (1991) analyzed days open and service interval of Holsteins, using a model containing sire and maternal grandsire of cow, and reported that nonadditive variance was equal to or larger than additive variance for days open and length of service period. In particular, dominance variance was greater than additive, and additive by additive variance was smaller. However, Hoeschele cautioned that whether upper bounds of these traits were restricted had a large effect on the results. Beckett et al. (1979) assessed specific combining abilities through crosses among 6 inbred lines of Holsteins and reported significant heterosis for days open (20.6 fewer days open) when the inbred lines were crossed.

Heterosis indicates the presence of nonadditive genetic variation (dominance or epistasis). "Almost without exception, crossbred animals have exhibited greater reproductive fitness than the parent breeds" (Warwick and Legates, 1979). Currently, there is re- newed interest in crossbreeding in dairy cattle, primarily to improve reproductive efficiency. Wall et al. (2003) estimated heterosis for cow fertility from the introduction of Holstein genes into British Friesians. Maternal heterosis effects on 56-d NR and number of inseminations were not significant, but days to first service decreased significantly due to increased cow heterosis.

Reproductive traits are adversely affected by inbreeding, suggesting the presence of nonadditive genetic variation. Increases in days open per $10 \%$ increase in inbreeding were estimated to be $23 \mathrm{~d}$ by Hermas et al. (1987) and $7 \mathrm{~d}$ by Beckett et al. (1979). Pulkkinen et al. (1997) found that inbreeding of cow affected 56-d NR, whereas inbreeding of the embryo mainly affected calving rate. Hoeschele (1991) predicted that a $10 \%$ inbreeding level in Holstein cows would increase days open by only $0.3 \mathrm{~d}$. Cassell et al. (2003) estimated that 10\% inbreeding decreased $70-d$ NR by about $2 \%$ per $10 \%$ increase in maternal inbreeding and about $1 \%$ per $10 \%$ increase in fetal inbreeding for Holstein data across lactations. In British Friesians, Wall et al. (2003) found that 56-d NR decreased by $1 \%$ per $10 \%$ maternal inbreeding.

Our objectives were to estimate additive and nonadditive genetic effects, inbreeding effects, and contribution of DUMPS and CVM carriers to embryonic mortality, as measured by 70-d NR. Specific interactions of service sire with sire of cow were estimated using a dominance relationship matrix (Hoeschele, 1991).

\section{MATERIALS AND METHODS}

\section{Data}

Original data files containing all reported service dates and service sires for 4,503,958 lactations were provided by Dairy Records Management Systems (Raleigh, NC), AgSource (Verona, WI), and Minnesota DHIA (Buffalo, MN). Data were first services from January 1, 1995, to August 2001. Observations were omitted if $70 \mathrm{~d}$ had not elapsed from first insemination to last reported dates. Edits restricted the data to Holstein cows with valid Holstein sire identification, valid sequential numbered services, and only AI first services. Of the remaining 3,339,440 lactations, 368,988 were omitted for conflicting service dates or for unusable sire or service sire identification.

Computational requirements were reduced by restricting records to those with both sire and service sire in a list of 1,251 bulls that had at least 100 daughters and at least 500 services. This edit reduced the data set to 1,739,055 records. First services were declared to have failed if rebreeding occurred to any sire whether in the list of 1,251 bulls or not. 
Table 1. Least squares estimates of parity effects on 70-d nonreturn rate percentage compared with parity 1

\begin{tabular}{llll}
\hline Parity & Estimate & SE & $t$-value \\
\hline 1 & 0.0 & - & - \\
2 & -2.8 & 0.08 & 35.7 \\
3 & -3.3 & 0.09 & 36.7 \\
4 & -4.0 & 0.11 & 36.4 \\
5 & -5.9 & 0.11 & 52.9 \\
\hline
\end{tabular}

Nonreturn rate at $70 \mathrm{~d}$ was defined as 0 if a second service was reported before $70 \mathrm{~d}$ following first service or as 100 if no second service was reported by $70 \mathrm{~d}$ so that results were expressed as percentages rather than fractions. Threshold models could be used for analysis of NR because the distribution is binomial, but advantages are small (Weller and Ron, 1992), and thus a linear model was used. The definition of the trait (number of days elapsed before subsequent insemination) affects the degree to which pregnancy loss is reflected. Traits such as 56-d NR reflect fewer losses than 168-d NR (Persson, 2003), and actual conception rate is lower than NR because nonpregnant cows are not always rebred within $70 \mathrm{~d}$.

Simultaneous estimation of all effects would be desirable but was not possible with the number of observations and available software. Thus, parity effects $\left(\mathrm{p}_{\mathrm{i}}\right)$ were estimated by least squares analysis within herd-year-season $\left(\right.$ hys $\left._{\mathrm{j}}\right)$ and the estimates were used to adjust NR (Table 1). The 2 seasons formed were June-October and November-May. Nonreturn rate for November-May was 5.8\% higher than for June-October based on a preliminary least squares analysis of month of first-service effects.

Observations for NR $\left(\mathrm{y}_{\mathrm{ijk} k \mathrm{~m}}\right)$ were modeled as a trait of the potential embryo resulting from the insemination, with the inseminated cow considered as the dam and the service sire as the sire. Main effects of service sire $\left(\mathrm{s}_{\mathrm{k}}\right)$ and sire of cow $\left(\mathrm{mgs}_{\mathrm{l}}\right)$ were estimated by REML using the models:

$$
\begin{gathered}
y_{i j k l m}-\hat{p}_{i}=h_{y s}+s_{k}+e_{i j k l m}, \\
y_{i j k l m}-\hat{p}_{i}=h y s_{j}+\operatorname{mgs}_{l}+e_{i j k l m},
\end{gathered}
$$

where $\mathrm{e}_{\mathrm{ijkl}}$ is a random residual. A relationship matrix was included for effect of sire of cow but not for service sire. The $\mathrm{y}_{\mathrm{ijklm}}$ were then adjusted for main effects of parity, sire, and maternal grandsire in the interaction analysis. Differences in bull health or semen dilution rate may change the effect of service sire across time, but the model did not account for such changes.

Adjusted NR was evaluated by a model that included a linear regression $(b)$ on fetal inbreeding $\left(\mathrm{F}_{\mathrm{kl}}\right)$, herd- year-season, and interaction $\left(\mathrm{d}_{\mathrm{kl}}\right)$ of service sire with sire of cow:

$$
\mathrm{y}_{\mathrm{ijk} \mathrm{k} m}-\hat{\mathrm{p}}_{\mathrm{i}}-\hat{\mathrm{s}}_{\mathrm{k}}-\mathrm{mg} \hat{\mathrm{s}}_{1}=\mathrm{hys}_{\mathrm{j}}+\mathrm{bF}_{\mathrm{kl}}+\mathrm{d}_{\mathrm{kl}}+\mathrm{e}_{\mathrm{ijkl} \mathrm{m}} \text {. }
$$

Dominance relationships among $d_{k l}$ were traced through sires and maternal grandsires of the service sires and the sires of cows, and interaction variance was estimated by the tilde-hat approximation to REML. The methods and computer programs were those developed by Hoeschele (1991) except that the interactions now are for the sire and maternal grandsire of the embryo rather than the cow. Inbreeding coefficients were underestimated because the pedigrees were traced only through the sires and maternal grandsires of the 1,251 most popular bulls.

A supplemental analysis was conducted to determine if CVM and DUMPS genotypes explained variation in the interaction estimates. Available genotyping results were obtained for the 1,251 service sires and sires of cows. Categories for each were: tested positive $(+)$, tested negative (-), and not tested (...). Effects fit were sire genotype, maternal grandsire genotype, and interaction of sire genotype with maternal grandsire genotype.

\section{RESULTS AND DISCUSSION}

The estimates of percentage of variation were service bull $0.36 \%$, sire of cow $0.24 \%$, and interaction $0.18 \%$. The sire of cow estimate corresponds to a heritability of $1 \%$ as a trait of the cow, and the interaction estimate corresponds to dominance variance of $2.8 \%$ as a trait of the embryo because sire-maternal grandsire interactions contain 1/16 of the dominance variance (Hoeschele, 1991). Estimated variances for service sire and sire of cow agree with previous studies and indicate that additive effects for NR are small, whereas nonadditive effects are somewhat larger. Standard errors of the variances were not available, and heritability of NR as a trait of the embryo was not estimable because the dam's contribution includes a maternal effect and the service sire's effect includes a permanent environmental effect.

The linear regression on inbreeding was $-0.096 \%$ per $1 \%$ increase in inbreeding of embryo. This agrees well with results of Cassell et al. (2003) even though their pedigrees were traced through sires and dams, whereas ours were traced only through sires and maternal grandsires. A regression of this magnitude could be explained by $20 \%$ of animals carrying recessive defects that cause embryos to be lost by $70 \mathrm{~d}$. Responses to inbreeding may not always be linear, but deviations from linearity were not examined in this study. 
Table 2. Interaction of service sire with sire of cow for 70-d nonreturn rate (NR)

\begin{tabular}{|c|c|c|c|c|c|c|}
\hline \multicolumn{2}{|l|}{ Service sire } & \multicolumn{2}{|l|}{ Cow sire } & \multirow{2}{*}{$\begin{array}{l}\text { 70-d NR } \\
\text { deviation } \\
(\%)\end{array}$} & \multirow{2}{*}{$\begin{array}{l}\text { Embryo } \\
\text { inbreeding } \\
(\%)\end{array}$} & \multirow[b]{2}{*}{$\begin{array}{l}\text { Services } \\
(\text { no. })^{2}\end{array}$} \\
\hline Name & $\begin{array}{l}\text { CVM } \\
\text { status }^{1}\end{array}$ & Name & $\begin{array}{l}\text { CVM } \\
\text { status }^{1}\end{array}$ & & & \\
\hline United Nick & $\ldots$ & Norrielake Cleitus Luke & $\ldots$ & -3.6 & 4.7 & 124 \\
\hline Maizefield Bellwood & - & Maizefield Bellwood & - & -3.4 & 25.0 & 33 \\
\hline Stardell Valiant Winken & - & To-Mar Blackstar & - & -3.2 & 0.0 & 66 \\
\hline \multicolumn{7}{|l|}{$\begin{array}{l}\text { Best } 5 \text { interactions (including } \\
\text { inbreeding effects) }\end{array}$} \\
\hline Paradise-R Cleitus Mathie & + & Regancrest Mascot Dello & - & 2.9 & 0.2 & 199 \\
\hline Paradise-R Roebuck & + & MJR Blackstar Emory & - & 2.8 & 0.0 & 502 \\
\hline Paradise-R Cleitus Mathie & + & Shen-Val NV LM Formation & $\ldots$ & 2.7 & 1.6 & 208 \\
\hline Paradise-R Cleitus Mathie & + & Scil Buckeye & $\ldots$ & 2.7 & 0.0 & 227 \\
\hline Coyne Farms Bonanza & - & Howcrest Aristides & - & 2.7 & 3.1 & 189 \\
\hline Stardell Valiant Winken & - & Robthom Integrity & - & -3.1 & 0.8 & 251 \\
\hline Schutzs Brass Bell & $\ldots$ & Pen-Col Duster & - & -2.8 & 0.0 & 217 \\
\hline \multicolumn{7}{|l|}{$\begin{array}{l}\text { Best } 5 \text { interactions (excluding } \\
\text { inbreeding effects) }\end{array}$} \\
\hline Coyne Farms Bonanza & - & Howcrest Aristides & - & 3.0 & 3.1 & 189 \\
\hline Paradise-R Cleitus Mathie & + & Regancrest Mascot Dello & - & 2.9 & 0.2 & 199 \\
\hline Paradise-R Cleitus Mathie & + & Shen-Val NV LM Formation & $\ldots$ & 2.9 & 1.6 & 208 \\
\hline Shen-Val NV LM Fashion & - & The Choice of Mark Adam & - & 2.8 & 4.0 & 121 \\
\hline Paradise-R Roebuck & + & MJR Blackstar Emory & - & 2.8 & 0.0 & 502 \\
\hline
\end{tabular}

${ }^{1}$ Testing status for complex vertebral malformation (CVM): Negative (-), positive (+), and not tested (...)

${ }^{2}$ Includes reciprocal cross services.

Reliabilities of interaction estimates are improved by considering dominance relationships but depend primarily on the number of observations per service sire by sire of cow subclass. The average was only 6 , but 50 subclasses had $>500$ observations (reliability of $>50 \%$ ). The largest subclass frequency was 2,077 . Data included 348 bulls mated to their own daughters (maximum was 154 for Paradise-R Cleitus Mathie).

Table 2 contains the bull combinations with the worst 5 and best 5 interactions, with inbreeding effects both included and excluded. The estimates of interactions including inbreeding ranged from -3.6 to $2.9 \%$ (relative to a mean NR of 56\%). The interaction estimates with inbreeding effects excluded ranged from -3.2 to $3.0 \%$. One of the worst interactions in Table 2 was for the mating of Maizefield Bellwood to his own daughters $(-3.4 \%)$, and there was a general tendency for the worst interactions to involve sire-daughter matings. Sire-daughter mating has been suggested as a simple method to uncover genetic defects (VanVleck, 1993).

The most favorable interactions are expected to involve bulls least related to each other (less likely that both carry the same genetic defect affecting embryonic or fetal death). The maximum inbreeding of an embryo among the combinations in Table 2 (other than siredaughter) was $4.7 \%$. Table 2 shows that adjustment for inbreeding had little effect on the best 5 interactions because the genetic relationship between the 2 bulls involved was small. Reliabilities are low for most predicted interactions because of small subclass numbers and interaction variance.

Effects of CVM and DUMPS were investigated using available genotype testing results $(+,-$, or ...). Of a total of 369,017 bull combinations, 2,195 involved 2 known CVM carriers. The most numerous carrier $\times$ carrier combination was Paradise-R Cleitus Mathie $\times$ Highlight Mr Mark Cinder (792). Only 2 of the worst combinations in Table 2 could possibly involve CVM carrier $\times$ carrier (where both bulls were untested). In fact, only 2 bulls in Table 2 were known CVM carriers (Mathie and Roebuck). Only 1 of the 1,251 bulls in this study (Happy Herd Beautician) was a known DUMPS carrier; thus, the edited data included no known carrier $\times$ carrier matings for DUMPS. Effects of CVM and DUMPS were not statistically significant. The lack of effect of CVM genotype on 70-d NR agrees with results of Persson (2003), who found an effect on 168-d NR 
but not on 28- or 56-d NR. Agerholm et al. (2001) reported that a few fetuses homozygous for CVM might survive until term, suggesting that the expression of the CVM gene occurs later in gestation rather than earlier.

Bulls carrying previously unknown defects affecting NR might be detected by examining the most extremely negative interactions. However, individual defects are not obvious from Table 2 . Note that estimated interactions include information from related interactions. For example, the interaction of Winken with Blackstar includes information from the reciprocal cross and from matings of Winken's close relatives to Blackstar's close relatives.

Embryo losses within $70 \mathrm{~d}$ are not reported by producers because such losses leave no visible evidence. Statistical detection is difficult because the trait NR includes a substantial proportion of returns to service that are due to fertilization failure. Some interactions could be caused by the cow's immune response to sperm or other factors before fertilization. Santos et al. (2004) concluded that $76 \%$ of inseminations result in fertilization, but only $60 \%$ of fertilizations are maintained until term. Interaction studies for stillbirths and for later gestation losses could be useful. Most embryo and fetal losses continue to be unexplained.

\section{CONCLUSIONS}

Increased inbreeding of embryos had a substantial negative impact on conception and $70 \mathrm{~d}$ survival after first insemination (about 1\% loss per 10\% increase in inbreeding). Variances for service sire, sire of cow, and interaction each contributed $<1 \%$ of phenotypic variance, but dominance variance was large compared with additive variance. Genotypes of bulls for DUMPS and CVM were not significant sources of variation in $70 \mathrm{~d}$ survival because DUMPS has almost been eliminated and CVM losses occur later in gestation. Carrier by carrier matings for CVM most frequently involved Paradise-R Cleitus Mathie (the most frequent combination was 792 with Highlight Mr Mark Cinder).

Matings of bulls to their own daughters had some of the most negative predicted interaction effects, such as $-3.4 \%$ for Maizefield Bellwood based on information from 33 direct matings and other related matings within this family. Study of the most negative interactions, such as for Bellwood, might disclose previously unknown genetic defects. The substantial dominance variation in 70-d NR explains why crossbreeding and avoidance of inbreeding can lead to improved fertility.

\section{ACKNOWLEDGMENTS}

Manuscript review by Paul Miller and contributions of fertility data by Dairy Records Management Sys- tems, AgSource, and Minnesota DHIA are greatly appreciated.

\section{REFERENCES}

Agerholm, J. S., C. Bendixen, O. Andersen, and J. Arnbjerg. 2001. Complex vertebral malformation in Holstein calves. J. Vet. Diagn. Invest. 13:283-289.

Ayalon, N. 1981. Embryonic mortality in cattle. Zuchthygiene 16:97-109.

Beckett, R. C., T. M. Ludwick, E. R. Rader, H. C. Hines, and R. E. Pearson. 1979. Specific and general combining abilities for production and reproduction among lines of Holstein cattle. J. Dairy Sci. 62:613-621.

Cassell, B. G., V. Adamec, and R. E. Pearson. 2003. Maternal and fetal inbreeding depression for 70-day nonreturn and calving rate in Holsteins and Jerseys. J. Dairy Sci. 86:2977-2983.

Clay, J. S., B. T. McDaniel, and C. H. Brown. 2003. Variances of and correlations among progeny tests for reproductive traits of cows sired by AI bulls. J. Dairy Sci. 87:2307-2313.

Gustavsson, I. 1979. Distribution and effects of the 1/29 Robertsonian translocation in cattle. J. Dairy Sci. 62:825-835.

Hermas, S. A., C. W. Young, and J. W. Rust. 1987. Effects of mild inbreeding on productive and reproductive performance of Guernsey cattle. J. Dairy Sci. 70:712-721.

Hoeschele, I. 1991. Additive and nonadditive genetic variance in female fertility of Holsteins. J. Dairy Sci. 74:1743-1752.

Iwasaki, S., and T. Nakahara. 1990. Cell number and incidence of chromosomal abnormalities in bovine blastocytes fertilized in vitro followed by culture in vitro or in vivo in rabbit oviducts. Theriogenology 33:669-675.

Kuhn, M. T., J. L. Hutchison, and C. P. Van Tassell. 2005. Effects of complex vertebral malformation gene on production and reproduction. J. Dairy Sci. 88(Suppl. 1):140. (Abstr.)

Multistate Project S-284. 2002. Genetic enhancement of health and survival for dairy cattle. Project summary. http://www.ans. iowastate.edu/research/S284/project.html

Nino-Soto, M. I., and W. A. King. 2004. Genetic factors that affect normal reproduction and fertility in domestic cattle. Proc. 23rd World Buiatrics Congress, Quebec, Canada. http://www.ivis.org/ proceedings/wbc/wbc2004/WBC2004-NinoSoto-simple.pdf

Persson, A. 2003. Effect of the genetic defect Complex Vertebral Malformation on fertility in Swedish Holstein cattle. Undergraduate Thesis, Swedish Agricultural University, Uppsala.

Pulkkinen, T. I., T. van der Lende, A. F. Groen, L. M. T. E. Kaal, and J. J. Zonderland. 1997. The effect of inbreeding on components of dairy cattle fertility as calculated from non-return data, using a multiphasic logistic function. Interbull Bull. 18:74-77.

Robinson, J. L., D. B. Dombrowski, G. W. Harpestad, and R. D. Shanks. 1984. Detection and prevalence of UMP synthase deficiency among dairy cattle. J. Hered. 75:277-280.

Santos, J. E. P., W. W. Thatcher, R. C. Chebel, R. L. A. Cerri, and K. N. Galvao. 2004. The effect of embryonic death rates in cattle on the efficacy of estrus synchronization programs. Anim. Reprod. Sci. 83:513-535.

Sattler, C. G. 2002. Update on CVM research. Proc. 19th Tech. Conf. Artificial Insemination and Reproduction. Natl. Assoc. Anim. Breeders, Columbia, MO.

Shanks, R. D., and J. L. Robinson. 1989. Embryonic mortality attributed to inherited deficiency of uridine monophosphate synthase. J. Dairy Sci. 72:3035-3039.

VanRaden, P. M., A. H. Sanders, M. E. Tooker, R. H. Miller, H. D. Norman, and G. R. Wiggans. 2004. Development of a national genetic evaluation for cow fertility. J. Dairy Sci. 87:2285-2292.

VanVleck, L. D. 1993. Pages 43-45 in Selection Index and Introduction to Mixed Model Methods. CRC Press Inc., Boca Raton, FL.

Vasconcelos, J. L. M., R. W. Silcox, J. A. Lacerda, J. R. Pursley, and M. C. Wiltbank. 1997. Pregnancy rate, pregnancy loss, and response to heat stress after AI at 2 different times from ovulation in dairy cows. Biol. Reprod. 56:230. 
Wall, E., S. Brotherstone, J. F. Kearney, J. A. Wooliams, and M. P. Coffey. 2003. Effect of including inbreeding, heterosis and recombination loss in prediction of breeding values for fertility traits. Interbull Bull. 31:117-121.

Warwick, E. J., and J. E. Legates. 1979. Breeding and Improvement of Farm Animals. 7th ed. McGraw-Hill Book Company, New York, NY.

Weigel, K. A., and R. Rekaya. 2000. Genetic parameters for reproductive traits of Holstein cattle from California and Minnesota. J. Dairy Sci. 83:1072-1080.
Weller, J. I., and M. Ron. 1992. Genetic analysis of fertility traits in Israeli Holsteins by linear and threshold models. J. Dairy Sci. 75:2541-2548.

Wijeratne, W. V. S. 1973. A population study of apparent embryonic mortality in cattle with special reference to genetic factors. Anim. Prod. 16:251-259.

Zavy, M. T., and R. D. Geisart. 1994. Embryonic mortality in cattle. Pages 99-141 in Embryonic Mortality in Domestic Species. CRC Press, Inc., Boca Raton, FL. 